\title{
No easy route to non-proliferation
}

NOWHERE has the interrelationship between politics and technology become more entangled than in discussing the relationship between the spread of nuclear energy and the proliferation of nuclear weapons. To candidates in the 1976 US presidential campaign, the issue seemed relatively straightforward: the greater the availability of plutonium either through the reprocessing of spent nuclear fuel or through the deployment of fast breeder reactors - the greater the chance that some of this would be diverted to military purposes. Domestically, this philosophy became relatively easy to institutionalise in the Nonproliferation Act of 1977. Internationally it has fallen on sceptical ears.

The final report of the International Nuclear Fuel Cycle Evaluation (INFCE), initiated by President Carter over two years ago in an attempt to generate an international consensus behind the US strategy, has ended up a long way from endorsing his position. Admittedly there are parts of the final report from which the US can take satisfaction. For example, the nations taking part in the study agreed in general that sensitive nuclear facilities capable of producing weapons-grade material, such as reprocessing and enrichment plants, should be limited to as few countries as possible. And the report also confirms the US view that reprocessing is not a prerequisite for the disposal of nuclear wastes, and of marginal economic significance for thermal reactors.

US negotiators are also claiming solace from the fact that, although they have been unable to secure agreement on slowing down the deployment of fast breeders in the interests of nonproliferation, they have at least placed the issue more prominently than before on the international agenda. But this victory is, in many ways, a Pyrrhic one. INFCE did not agree to support any generalisations about the comparative proliferation risks of different fuel cycles. Indeed during its deliberations, the international deployment of fast breeder programmes, particularly in countries such as France concerned about guaranteed future access to uranium supplies, seems to have increased.

What the debate has lacked is a climate of trust. And this is as true for the relationship between the US and its fellow nuclear suppliers as between the suppliers and their customers. Many countries were upset, not so much by the US strategy, but by the apparent strong arm tactics by which it was seeking to impose it unilaterally. President Carter declared his intention that the US. "Should provide strong leadership, using our own exports of nuclear fuel and technology to persuade other countries not to seek or sell the technology to make bombs."'Many took exception to this attempt to use economic hegemony to force the rules of the game covering international trade in nuclear technology particularly at a time when the US and European industries seemed about to compete for lucrative third world markets.

The value of INFCE is that it has placed many of the issues raised by President Carter in broader perspective. We now know, for example, that there is unlikely to be any one technical fix to the proliferation question, and that the thorium-cycle does not necessarily offer any great advantages in this respect. We also know that the lack or adequacy of uranium supplies cannot be demonstrated simply. But whether we are any closer to reducing the dangers of proliferation is unclear.

One problem is that, whatever the detailed conclusions and recommendations of the report, any message that fast breeders are safe could, unless carefully handled, lead to unwarranted complacency. The report has successfully argued that political issues with regard to restricting proliferation cannot be reduced to technical questions relating solely to the availability of fuels or reactor technology. But it conveys an optimism about the ability of political institutions to cope with the problems that may, in practice, turn out to be equally overstated.

Perhaps this optimism is no greater than that with which President Carter swept into office three and half years ago, determined to demonstrate that controlling the hazards of nuclear power - or for that matter eliminating infringements of human rights - was little more than a question of political will. But such arguments were conceived in the calmer days of the mid-1970s, when the short-term stability of international relations made it possible to argue in terms of long-term strategies.

In the aftermath of Iran and Afghanistan, the climate has changed dramatically. Yet the irony is that, just at a time when the US is trying to restrain countries such as Pakistan and India from a rush to nuclear weapons, and arguing the need for effective international controls, it is engaged with other western nations in boosting its own nuclear arsenal.

Given this situation, it is difficult to see emerging the "Bargain of confidence" urged last month by a study group convened by the Royal Institute for International Affairs, with support from the Rockefeller Foundation. Indeed it is the reality of self-interest that needs to be addressed if we are to make genuine progress towards reducing the threat of nuclear war. Just as there are no technical fixes to the proliferation problem, so we should not be fooled into thinking there are any quick political fixes.

Doing what we can to raise the global standard of living, and reducing the tensions that flow from inequities in the distribution of wealth and power, will in the long run be the only way of removing the incentive for nuclear war. In the short term, efforts to conclude a comprehensive ban on the testing of new weapons, and to maintain pressure for arms limitation treaties such as SALT 2, would be a welcome show of good faith. A world built on conflicts and tensions - with or without fast breeders - can only encourage the instabilities that point to nuclear disaster. 